
3

\title{
Comparison of Childbirth Experiences and Postpartum Depression in Three Groups of Primiparous Women with no Participation, Irregular Participation and Regular Participation in Childbirth Preparation Classes
}

\section{Robab Hassanzadeh}

Tabriz University of Medical Sciences Faculty of Nursing and Midwifery

\section{Fateme Abbas-Alizadeh}

Tabriz University of Medical Sciences

\section{Shahla Meedya}

University of Wollongong Faculty of Science Medicine and Health

\section{Sakineh Mohammad-Alizadeh Charandabi}

Tabriz University of Medical Sciences Faculty of Nursing and Midwifery

Mojgan Mirghafourvand ( $\square$ mirghafourvand@gmail.com )

Tabriz University of Medical Sciences

\section{Research}

Keywords: Childbirth Experience, Postpartum Depression, Childbirth Preparation Classes

Posted Date: February 27th, 2020

DOl: https://doi.org/10.21203/rs.2.24757/v1

License: (c) (1) This work is licensed under a Creative Commons Attribution 4.0 International License. Read Full License 


\section{Abstract}

Background Assessment of women's childbirth experience is an important indicator of maternal care systems. Positive childbirth experiences improve mothers' health, whereas negative childbirth experiences can cause psychological stresses and, in extreme cases, may lead to postpartum depression. This study compared childbirth experiences and postpartum depression levels in three groups of primiparous women with no participation, irregular participation, and regular participation in childbirth preparation classes.

Methods In this cohort study, 204 primiparous women at 35-37 weeks of gestation were selected using cluster sampling from the health centers of Tabriz, Iran. The participants were assigned to three groups of no participation, irregular participation (attending 1-3 sessions), and regular participation (attending 4-8 sessions) in childbirth preparation classes. Interviews were conducted one month after delivery to complete the Childbirth Experience Questionnaire (CEQ) and Edinburgh Postnatal Depression Scale (EPDS). The general linear model (GLM) was used to compare childbirth experience and postpartum depression among groups.

Results Based on the general linear model, the mean score of childbirth experience in women in the regular participation group was significantly higher than those of women in irregular participation ( $P=$ 0.032) and in no participation $(P<0.001)$ groups. In addition, the mean score of postpartum depression was significantly lower in women in the regular participation group than that of the women in the no participation group $(P<0.001)$. However, no significant difference was found between the regular and irregular participation groups in terms of postpartum depression levels $(P=0.257)$.

Conclusion Prenatal training classes improved childbirth experience and reduced postpartum depression levels. These training classes seem to improve mothers' health by increasing their knowledge and awareness of their abilities to endure labor pain.

Ethical Code IR.TBZMED.REC.1398.066

\section{Plain English Summary}

Childbirth preparation classes are a perinatal health promotion and educational activities offered to pregnant women, aimed at increasing their knowledge regarding pregnancy, labour, delivery and postpartum. This study was carried out to compare childbirth experience and postpartum depression in three groups of primiparous women with no participation, irregular participation, and regular participation in childbirth preparation classes. In this cohort study, Two hundred and four primiparous women were selected randomly from health complexes located in Tabriz, Iran at gestational age of 35-37 weeks and followed up until one month after delivery. Childbirth Experience Questionnaire and Edinburgh Postnatal Depression Scale were used to obtain information. The results showed that the mean score of childbirth experience in women in the regular participation group was significantly higher than those of women in irregular participation and in no participation group. In addition, the mean score of postpartum depressive 
symptoms was significantly lower in women in the regular participation group than that of the women in the no participation group. The study revealed childbirth preparation classes improved childbirth experience and reduced postpartum depression levels.

\section{Background}

Childbirth is one of the most important events in women's lives and childbirth experience, as an individual life event that combines several physiological and subjective psychological processes, is influenced by social, environmental, and organizational contexts and policies [1]. Experiences gained by women during childbirth are considered one of the major outcomes of this process that will stay with women throughout their lives [2]. According to a cohort study in Japan, women clearly remember their labor experiences even 5 years after delivery [3]. Unfortunately, reproductive health services have conventionally focused their efforts and resources on reducing perinatal mortality and have paid less attention to mothers' childbirth experiences and their beliefs about motherhood and labor $[4,5]$. This is while childbirth experience significantly affects physical and mental health of women in the postpartum period as well as their relationships with their children. Positive childbirth experiences improve maternal health, enhance mothers' self-worth and self-esteem and facilitate mother-child relationships [6, 7], whereas negative experiences both affect women's breastfeeding abilities [8], their decisions to get pregnant again (9), and the type of delivery in subsequent pregnancies $[10,11]$ and can cause psychological stresses and, in extreme cases, may lead to postpartum depression [6, 7]. This reduces the mother's quality of life, weakens mother-child relationships and leads to abnormal physical, psychological and emotional development of the child [12]. The effects of a positive or negative childbirth experience may linger for years $[6,13]$.

Many women attend childbirth preparation classes to prepare themselves for delivery, which is an important change in their lives [14]. In these classes, they are provided with information and trained to perform physical exercises and to improve their self-control capabilities, which may increase their satisfaction with the delivery experience $[15,16]$. These classes can also help women quickly recognize the signs and symptoms of postpartum depression [17], and increase women's understanding of childbirth in order to better meet their needs [18]. However, lack of awareness and/or provision of inconsistent or contradictory information in these classes can lead to negative childbirth experiences [19, 20]. Moreover, providing mothers with too much new information in a short time may be ineffective, and lack of time to engage in discussion about and transfer the knowledge and practice of pain relief techniques may diminish the benefits of childbirth preparation classes [21].

The results of some studies conducted in China [22], the Netherlands [23], Turkey [24], the United States [12] and the Caucasus [25] have shown decreases in mental problems and improvements in delivery experience of women who had attended prenatal training classes. In Iran, childbirth preparation classes have been held for pregnant women since 2008 [26]. However, the authors did not find any study on the effects of these classes on childbirth experiences and postpartum depression levels. The study of mothers' childbirth experiences helps caregivers better understand mothers' needs and expectations, and 
make effective need-based interventions in order to increase mothers' satisfaction levels $[1,27]$. This study aimed to compare childbirth experience and postpartum depression in three groups of primiparous women with no participation, irregular participation, and regular participation in childbirth preparation classes.

\section{Methods}

\section{Type of research and participants}

In this cohort study, a part of a mixed methods research with an already published protocol [28], 204 primiparous women at 35-37 weeks of gestation were divided into the three groups of regular participation (attending 4-8 sessions), irregular participation (attending 1-3 sessions), and no participation in childbirth preparation classes. The study inclusion criteria consisted of living in Tabriz city, being primiparous, and having a gestational age of 35-37 weeks. The study exclusion criteria consisted of having a multiple pregnancy, being multiparous, non-cephalic presentation, obstetric problems such as placenta previa, inclination to deliver babies via elective cesarean section, history of major diseases such as cardiovascular diseases, diabetes, chronic hypertension, preeclampsia, history of depression requiring medicine, and occurrence of important stressful event in the past 6 months such as death of a close relative, separation from the partner, etc.

\section{Sample size}

The sample size in this study was calculated based on the scores for the variable of postpartum depression using G Power software. According to the results obtained by Duncan et al. [12], on the relationship between prenatal education and postpartum depression, and considering $M_{1}=12.9$ (the mean score for postpartum depression in control group), $\mathrm{SD}_{1}=9.1, \mathrm{M}_{2}=8.3$ (the mean score for postpartum depression in the group participating in the childbirth preparation course), $\mathrm{SD}_{2}=6.1$, two sided $a=0.05$, and power $=90 \%$, the calculated number of participants for each group will be 61 . Assuming an attrition rate of 10\%, the final sample size will be 68 in each group and 204 in all.

\section{Sampling}

Using cluster sampling, 7 of the 20 health complexes located in Tabriz, Iran, were randomly selected. Simple random sampling was then used to select the participants among all primiparous women admitted to these health centers affiliated with the selected complexes (Each health complex consisted of 4-5 health centers and the samples were selected from 29 centers). Using proportional allocation, the eligible women at 35-37 weeks of gestation were randomly selected from each center and divided into the three groups of regular participation (attending 4-8 sessions), irregular participation (attending 1-3 sessions) and no participation in childbirth preparation classes. The eligible women were enrolled and informed of the research objectives and methods. Informed consent was obtained from those who were willing to participate in the study. The socio-demographic and obstetrics questionnaires were completed in interviews held with the participants. The participants gave their phone numbers to the researchers 
and, one month after delivery, the researchers called the participants and asked them to visit their respective health centers to complete the Childbirth Experience Questionnaire (CEQ) and Edinburgh Postnatal Depression Scale (EPDS).

\section{Data collection tools}

The data were collected using socio-demographic and obstetrics characteristics questionnaire, CEQ and EPDS.

\section{Socio-demographic and obstetrics characteristics questionnaire}

The socio-demographic characteristics questionnaire consisted of items such as age, age of first sexual experience, educational qualifications, occupation, body mass index (BMI), spouse's age, educational qualifications and occupation, level of support received from the spouse and marital satisfaction. The obstetrics characteristics questionnaire included items such as history of abortion, infertility, unwanted pregnancy, satisfaction with the fetal gender, type of delivery, place of delivery and delivery agent. The overall validity of this questionnaire was confirmed using face and content validity.

\section{Childbirth Experience Questionnaire (CEQ 2.0)}

This is a 23-item questionnaire that measures the childbirth experience of women. It consists of 4 domains including personal capacity (sense of control and personal feeling about childbirth and labor pain), professional support (information and midwifery care), perceived safety (sense of safety and childbirth memories), and participation (a woman's ability to change her position to relieve pain during labor and childbirth). The tool consists of 20 four-choice items, and 3 items are scored using a visual analogue scale (VAS). The validity and reliability of this tool have been confirmed in a population of U.S. women. The responses included strongly agree (score 4), often agree (score 3), often disagree (score 2), and strongly disagree (score 1). Scores that are given using the visual scale are converted to scores of 1-4 (scores of 0-40 receive score of $1 ; 41-60$ score of 2; 61-80 score of 3; and 80-100 score of 4). Items expressing negative concepts (experiencing severe pain, feeling tired, feeling afraid and having bad memories) receive negative scores. Higher mean scores indicate more positive childbirth experiences [29]. The psychometric properties of this tool have been approved by Ghanbari Homayi et al [30]. In this study, the reliability of this questionnaire was high (Cronbach's alpha $=0.92$ ).

\section{Edinburgh Postnatal Depression Scale (EPDS)}

This 10-item scale was developed by Cox et al. (1987) to measure prenatal and postpartum depression levels. It consists of 10 four-choice items. In some items, the options are arranged from low to high severity (items 1, 2, and 4) and in some they are arranged from high to low severity (items 3, 5, 6, 7, 8, 9 and 10). The scores given to each item range from 0 to 3 based on the severity of symptoms. The scores given to all items are summed up to produce the total depression score for each individual that can vary from 0 to 30 [31]. The psychometric properties of this scale have been approved by Montazeri et al. [32]. in this study, the reliability of this tool was measured using Cronbach's alpha (alpha $=0.81$ ). 


\section{Data analysis}

After completing the questionnaires, data were analyzed in SPSS-21. The normality of the quantitative data was assessed using the Kolmogorov-Smirnov test. The homogeneity of the study groups in terms of demographic details was assessed using the one-way ANOVA, the Chi-squared test, Chi-squared test for trend, and Fisher's exact test. The study groups were compared in terms of postpartum depression and childbirth experience using the one-way ANOVA in the bivariate analysis and the general linear model with the adjustment of certain demographic variables in the multivariate analysis. $P<0.05$ was taken as the significance level.

\section{Results}

No significant difference was found between the study groups in terms of demographic details such as woman's age and education, spouse's age, age at the onset of sexual life, BMI, and wanted pregnancy $(P>0.05)$, but there were significant differences between the three groups in terms of woman's occupation, spouse's education and occupation, income, spouse's support, and marital satisfaction $(P<0.05)$. The mean (standard deviation) age was 25.8 (5.7) years in the non-participation group, 27.0 (5.6) years in the irregularly-participation group, and 25.7 (4.7) years in the regularly-participation group ( $P=0.297)$. The majority of the women in the non-participation, irregularly-participation, and regularly-participation groups (76.5\%, $66.5 \%$, and $77.9 \%$, respectively) had adequate incomes. Less than half of the women in the nonparticipation group (41.9\%) had high school diploma, while $52.9 \%$ of the women in the irregularlyparticipation group and $41.9 \%$ of those in the regularly-participation group had university education. The majority of the women in the non-participation, irregularly-participation, and regularly-participation groups $(97.1 \%, 76.5 \%$, and $82.3 \%$, respectively) were housewife. About one-third of the spouses in the nonparticipation group (36.8\%) had high school diploma, while half of the spouses in the irregularlyparticipation (50\%) and regularly-participation (55.8\%) groups had university education. The majority of the women in the non-participation, irregularly-participation, and regularly-participation groups $(88.2 \%$, $89.7 \%$, and $88.2 \%$, respectively) had wanted pregnancies (Table 1 ).

Based on the one-way ANOVA, the mean (SD) scores of postpartum depression in women in the regular participation, irregular participation, and no participation groups were 4.1 (2.2), 4.9 (2.3) and 9.3 (4.7), respectively. The mean scores of postpartum depression in women in the regular $(P<0.001)$ and irregular $(P<0.001)$ participation groups were significantly lower than that of those in the no participation group. However, no significant difference was found between those in the regular and irregular participation groups in terms of postpartum depression levels $(P=0.150)$.

Some of the participants underwent cesarean section before the onset of labor pain; therefore, the sample size was reduced to 121 (regular participation group: $n=44$; irregular participation group: $n=26$; no participation group: $n=51$ ). The mean (SD) score of childbirth experience in women in the regular participation, irregular participation, and no participation groups were $3.2(0.41), 2.9(0.43)$ and $2.3(0.39)$, respectively. The mean scores of childbirth experience in women in the regular $(P<0.001)$ and irregular 
$(P<0.001)$ participation groups were significantly higher than that of women in no participation group. In addition, the mean score of childbirth experience in women in the regular participation group was significantly $(P=0.002)$ higher than that of the women in the irregular participation group (Table 2$)$.

After adjusting the variables of income, occupation, spouse's education and occupation, spouse's support and marital satisfaction, the general linear model results showed that the mean score of childbirth experience in women in the regular participation group was significantly higher than those of women in the irregular participation $(P=0.032)$ and no participation $(P<0.001)$ groups. In addition, the mean score of postpartum depression was significantly lower in women in the regular participation group than that of those in the no participation group $(P<0.001)$. However, no significant difference was found between the regular and irregular participation groups in terms of postpartum depression levels $(P=0.257)$ (Table 3$)$.

\section{Discussion}

After adjusting the variables of income, occupation, spouse's education and occupation, spouse's support and marital satisfaction, it was found that postpartum depression scores of women who regularly attended childbirth preparation classes were significantly lower than those obtained for women who did not attend these classes. However, there was no statistically significant difference between the regular and irregular participation groups in terms of postpartum depression scores. In line with our findings, Duncan et al. reported fewer symptoms of postpartum depression in the group of pregnant women who had received training interventions than in the control group members [12]. Similarly, Tadaharu et al. found that prenatal training reduced postpartum depression levels [33]. Considering that prenatal anxiety is known as an important risk factor for postpartum depression [13], childbirth preparation classes seem to reduce postpartum depression levels [6] by reducing prenatal fear and anxiety $[25,34]$ and preparing women psychologically for childbirth [34].

In this study, the childbirth experience scores of women who regularly attended childbirth preparation classes were significantly higher than those of women who attended these classes irregularly or did not attend them. In addition, the childbirth experience scores of women who attended childbirth preparation classes irregularly were significantly higher than those of women who did not attend these classes. Taheri et al. concluded in their review study that women who participated in prenatal training classes had better childbirth experiences [35]. Spinelli et al. also found similar results [36]. The results of the above studies are in line with those of the present research.

Prenatal education classes help women experience satisfactory labors with less pain [22,37]. The information received by women and the extent of their involvement in the decision-making process seem to affect their childbirth experience. Moreover, the comprehensive experience gained by women during the labor process is regarded as an important outcome of this process, which will stay with them throughout their lives [2]. Some studies have reported that fear increases negative childbirth experiences [38] and postpartum depression [12], and have argued that childbirth preparation training increases pregnant women's knowledge and awareness providing them with effective relaxation and pain relief techniques. 
Therefore, childbirth preparation training may reduce mothers' fear and anxiety levels [19, 39], inform them about their abilities to endure labor pain and lead to a positive childbirth experience [16]. A positive childbirth experience is an important goal in midwifery care, where childbirth is defined as a natural life event with the outcome of "alive and healthy mother and infant and satisfaction of individual needs" [38].

\section{Limitations and strengths}

The main limitation of this study is that the participants in this study consisted of primiparous pregnant women from the healthcare complexes from Tabriz city, Therefore, Generalizability of our study results is limited to multiparous women or primiparous pregnant women from other cities. Despite these limitations, this study has several strengths such as random sampling, being a cohort study and this is the first study to our knowledge to investigate the effects of childbirth preparation classes in Tabriz cityIran. Another strength of the study is that this study is carried out as a cohort study.

\section{Conclusion}

This study revealed benefits of participation in childbirth preparation classes, including a reduction in postpartum depression and a high level of satisfaction with the childbirth experience. Therefore, participation of pregnant women in childbirth preparation classes should be disseminated and childbirth preparation classes should be integrated in to standard perinatal care.

\section{Abbreviations}

CEQ: Childbirth experience questionnaire; EPDS: Edinburgh Postpartum Depression Scale.

\section{Declarations}

\section{Ethics approval and consent to participate}

Written informed consent has been obtained from each participant. This study has been approved by the Ethics Committee of the Tabriz University of Medical Sciences, Tabriz, Iran (code of ethics IR.TBZMED.REC.1398.066).

\section{Consent for publication}

Not applicable.

\section{Availability of data and materials}

The datasets used and analysed during the current study are available from the corresponding author on reasonable request.

\section{Competing interests}


The authors declare that they have no competing interests.

\section{Funding}

This study is funded by Tabriz University of Medical Sciences. The funding agency had no role in the design of the study, the collection, analysis, and interpretation of data and in writing the manuscript.

\section{Authors' contributions}

MM, FA, SMAC, SM and RH contributed to the design of the study. MM, RH and FA contributed to the implementation and analysis plan. MM, SMAC, SM and RH has written the first draft of this manuscript and all authors have critically read the text and contributed with inputs and revisions, and all authors read and approved the final manuscript.

\section{Acknowledgements}

The present article is part of a PhD thesis in midwifery with the code of ethics IR.TBZMED.REC.1398.066, obtained from the Ethics Committee of Tabriz University of Medical Sciences. We hereby wish to express our gratitude to this university's Research Deputy and the faculty members of the School of Nursing and Midwifery of the university for their extensive help and support and also to all the participants.

\section{References}

1. Larkin P, Begley CM, Devane D. Women's experiences of labour and birth: an evolutionary concept analysis. Midwifery. 2009;25(2):49-59.

2. Waldenstrom U. Women's memory of childbirth at two months and one year after the birth. Birth. 2003;30(4):248-54.

3. Takehara K, Noguchi M, Shimane T, Misago C. A longitudinal study of women's memories of their childbirth experiences at five years postpartum. BMC pregnancy and childbirth. 2014;14:221.

4. Ketting $E$, Esin A. Integrating sexual and reproductive health in primary health care in Europe: position paper of the European Forum for Primary Care. Quality in primary care. 2010;18(4):269-82.

5. Ten Hoope-Bender P, de Bernis L, Campbell J, Downe S, Fauveau V, Fogstad H, et al. Improvement of maternal and newborn health through midwifery.Lancet. 2014;384(9949):1226-35.

6. Fenaroli V, Molgora S, Dodaro S, Svelato A, Gesi L, Molidoro G, et al. The childbirth experience: obstetric and psychological predictors in Italian primiparous women. BMC pregnancy and childbirth. 2019;19(1):419.

7. Guittier MJ, Cedraschi C, Jamei N, Boulvain M, Guillemin F. Impact of mode of delivery on the birth experience in first-time mothers: a qualitative study. BMC pregnancy and childbirth. 2014;14:254.

8. Goodman P, Mackey MC, Tavakoli AS. Factors related to childbirth satisfaction. J Adv Nurs. 2004;46(2):212-9. 
9. Ryding EL. Investigation of 33 women who demanded a cesarean section for personal reasons. Acta Obstet Gynecol Scand. 1993;72(4):280-5.

10. Pang MW, Leung TN, Lau TK, Hang Chung TK. Impact of first childbirth on changes in women's preference for mode of delivery: follow-up of a longitudinal observational study. Birth. 2008;35(2):121-8.

11. Simkin P. Commentary: The Meaning of Labor Pain. Birth. 2000;27(4): 254-5 p.

12. Duncan LG, Cohn MA, Chao MT, Cook JG, Riccobono J, Bardacke N. Benefits of preparing for childbirth with mindfulness training: a randomized controlled trial with active comparison. BMC pregnancy and childbirth. 2017;17(1):140.

13. Bell AF, Andersson E. The birth experience and women's postnatal depression: A systematic review. Midwifery. 2016;39:112-23.

14. Leach J, Bowles B, Jansen L, Gibson M. Perceived Benefits of Childbirth Education on Future HealthCare Decision Making. J Perinat Educ. 2017;26(1):49-56.

15. Ho I, Holroyd E. Chinese women's perceptions of the effectiveness of antenatal education in the preparation for motherhood. J Adv Nurs. 2002;38(1):74-85.

16. Miquelutti MA, Cecatti JG, Makuch MY. Antenatal education and the birthing experience of Brazilian women: a qualitative study. BMC pregnancy and childbirth. 2013;13:171.

17. Zauderer C. Postpartum depression: how childbirth educators can help break the silence. T J Perinat Educ. 2009;18(2):23-31.

18. Pinar G, Avsar F, Aslantekin F. Evaluation of the Impact of Childbirth Education Classes in Turkey on Adaptation to Pregnancy Process, Concerns About Birth, Rate of Vaginal Birth, and Adaptation to Maternity: A Case-Control Study. Clin Nurs Res. 2018;27(3):315-42.

19. Bergstrom $M$, Kieler $\mathrm{H}$, Waldenstrom U. Effects of natural childbirth preparation versus standard antenatal education on epidural rates, experience of childbirth and parental stress in mothers and fathers: a randomised controlled multicentre trial. BJOG. 2009;116(9):1167-76.

20. Hallgren A, Kihlgren M, Norberg A, Forslin L. Women's perceptions of childbirth and childbirth education before and after education and birth. Midwifery. 1995;11(3):130-7.

21. Spiby H, Henderson B, Slade P, Escott D, Fraser RB. Strategies for coping with labour: does antenatal education translate into practice? J Adv Nurs. 1999;29(2):388-94.

22. Lee LY, Holroyd E. Evaluating the effect of childbirth education class: a mixed-method study. Int Nurs Rev. 2009;56(3):361-8.

23. Jakubiec D, Jagielska K, Karmowski M, Kubicka K, Karmowski A, Sobiech KA. Effect of attending childbirth education classes on psychological distress in pregnant women measured by means of the General Health Questionnaire. Adv Clin Exp Med. 2014;23(6):953-7.

24. Gokce Isbir G, Inci F, Onal H, Yildiz PD. The effects of antenatal education on fear of childbirth, maternal self-efficacy and post-traumatic stress disorder (PTSD) symptoms following childbirth: an experimental study. Appl Nurs Res. 2016;32:227-32. 
25. Stamler LL. The participants' views of childbirth education: is there congruency with an enablement framework for patient education? J Adv Nurs. 1998;28(5):939-47.

26. Ministry of Health and Medical Education. Preparation for childbirth, Educational guidance for Midwifes. 1st, editor. Tehran: Pejvak Arman 2015.

27. Dwamena F, Holmes-Rovner M, Gaulden CM, Jorgenson S, Sadigh G, Sikorskii A, et al. Interventions for providers to promote a patient-centred approach in clinical consultations. The Cochrane database of systematic reviews. 2012;12:Cd003267.

28. Hassanzadeh R, Abbas-Alizadeh F, Meedya S, Mohammad-Alizadeh-Charandabi S, Mirghafourvand M. Assessment of childbirth preparation classes: a parallel convergent mixed study. Reproductive health. 2019;16(1):160.

29. Walker KF, Wilson P, Bugg GJ, Dencker A, Thornton JG. Childbirth experience questionnaire: validating its use in the United Kingdom. BMC pregnancy and childbirth. 2015;15:86.

30. Ghanbari-Homayi S, Dencker A, Fardiazar Z, Jafarabadi MA, Mohammad-Alizadeh-Charandabi S, Meedya $S$, et al. Validation of the Iranian version of the childbirth experience questionnaire 2.0. BMC pregnancy and childbirth. 2019;19(1):465.

31. Cox JL, Holden JM, Sagovsky R. Detection of postnatal depression. Development of the 10-item Edinburgh Postnatal Depression Scale. Br J Psychiatry. 1987;150:782-6.

32. Montazeri A, Torkan B, Omidvari S. The Edinburgh Postnatal Depression Scale (EPDS): translation and validation study of the Iranian version. BMC Psychiatry. 2007;7:11.

33. Okano T, Nagata S, Hasegawa M, Nomura J, Kumar R. Effectiveness of antenatal education about postnatal depression: A comparison of two groups of Japanese mothers. $J$ Ment Health. 1998;7(2):191-8.

34. Koehn M. Contemporary Women's Perceptions of Childbirth Education. J Perinat Educ. 2008;17(1):11-8.

35. Taheri M, Takian A, Taghizadeh Z, Jafari N, Sarafraz N. Creating a positive perception of childbirth experience: systematic review and meta-analysis of prenatal and intrapartum interventions. Reproductive health. 2018;15(1):73.

36. Spinelli A, Baglio G, Donati S, Grandolfo ME, Osborn J. Do antenatal classes benefit the mother and her baby? The Journal of Maternal-Fetal \& Neonatal Medicine. 2003;13(2):94-101.

37. Lumley J, Brown S. Attenders and nonattenders at childbirth education classes in Australia: how do they and their births differ? Birth. 1993;20(3):123-30.

38. Nilsson C, Lundgren I, Karlstrom A, Hildingsson I. Self reported fear of childbirth and its association with women's birth experience and mode of delivery: a longitudinal population-based study. Women and birth. 2012;25(3):114-21.

39. Howharn C. Effects of childbirth preparation classes on self-efficacy in coping with labor pain in Thai primiparas. Univ Tex Austin Sch Nurs. 2001;15. 


\section{Tables}

Table 1. Characteristics of the study participants $(n=204)$

\begin{tabular}{|c|c|c|c|c|}
\hline \multirow[b]{2}{*}{ P-Value } & \multirow[b]{2}{*}{ Mean (SD) } & \multirow[b]{2}{*}{ Mean (SD) } & \multirow[b]{2}{*}{ Mean (SD) } & \multirow[t]{2}{*}{ Variable } \\
\hline & & & & \\
\hline $0.297^{\dagger}$ & $25.7(4.7)$ & $27.0(5.6)$ & $25.8(5.7)$ & Age (years) \\
\hline $0.212^{\dagger}$ & $30.8(4.2)$ & $32.0(5.0)$ & $30.9(4.2)$ & Spouse's Age \\
\hline \multirow[t]{5}{*}{$0.448^{\dagger}$} & $22.8(4.6)$ & $23.9(5.2)$ & $23.1(5.4)$ & $\begin{array}{l}\text { Age at the onset of sexual life } \\
\text { Education }\end{array}$ \\
\hline & $1(1.5)$ & $1(1.5)$ & $2(2.9)$ & Illiterate \\
\hline & $2(2.9)$ & $1(1.5)$ & $2(2.9)$ & Elementary \\
\hline & $8(11.8)$ & $10(14.7)$ & 9 (13.3) & Intermediate \\
\hline & $11(16.2)$ & $9(13.3)$ & 9 (13.3) & High school \\
\hline \multirow[t]{2}{*}{$0.083^{\ddagger \ddagger}$} & $18(26.5)$ & $11(16.2)$ & $28(41.2)$ & Diploma \\
\hline & $28(41.2)$ & $36(52.9)$ & $18(26.5)$ & $\begin{array}{c}\text { College } \\
\text { Occupation }\end{array}$ \\
\hline \multirow[t]{3}{*}{$0.001^{\text {㧊 }}$} & $56(82.3)$ & $52(76.5)$ & $66(9.7)$ & Housewife \\
\hline & $8(11.8)$ & $15(23.1)$ & $2(2.9)$ & Employee \\
\hline & $4(5.9)$ & $1(1.5)$ & 0 & $\begin{array}{l}\text { University student } \\
\text { Income }\end{array}$ \\
\hline \multirow[t]{3}{*}{$0.014^{\text {㧊 }}$} & $2(2.9)$ & $6(8.8)$ & $10(14.7)$ & Not at all sufficient \\
\hline & $53(77.9)$ & $45(66.2)$ & $52(76.5)$ & Relatively sufficient \\
\hline & $13(19.1)$ & $17(25.0)$ & $6(8.8)$ & $\begin{array}{l}\text { Completely sufficient } \\
\text { Spouse's Education }\end{array}$ \\
\hline \multirow[t]{6}{*}{$0.001^{\text {㧊 }}$} & 0 & $1(1.5)$ & $3(4.4)$ & Illiterate \\
\hline & $2(2.9)$ & $5(7.4)$ & 7 (10.3) & Elementary \\
\hline & $5(7.4)$ & $3(4.4)$ & $11(16.2)$ & Intermediate \\
\hline & $4(5.9)$ & $4(5.9)$ & 9 (13.3) & High school \\
\hline & $19(27.9)$ & $21(30.9)$ & $25(36.8)$ & Diploma \\
\hline & $38(55.8)$ & $34(50.0)$ & $13(19.1)$ & $\begin{array}{l}\text { College } \\
\text { Spouse's occupation }\end{array}$ \\
\hline \multirow[t]{4}{*}{$0.045^{\text {㧊 }}$} & $2(2.9)$ & $1(1.5)$ & $2(2.9)$ & Unemployed \\
\hline & $19(27.9)$ & $13(19.1)$ & $8(11.8)$ & Employed \\
\hline & $10(14.7)$ & $16(23.5)$ & $25(36.8)$ & Worker \\
\hline & $37(54.4)$ & $38(55.8)$ & 33 (48.5) & $\begin{array}{l}\text { Free Job } \\
\text { Spouse's support }\end{array}$ \\
\hline \multirow[t]{6}{*}{$>0.001$ 㧊 } & $41(72.1)$ & $34(50.0)$ & $20(29.4)$ & Too much \\
\hline & $16(23.5)$ & $20(29.4)$ & $22(32.4)$ & High \\
\hline & $10(14.7)$ & $14(20.6)$ & $24(35.3)$ & Average \\
\hline & 0 & 0 & $1(1.5)$ & Low \\
\hline & $1(1.5)$ & 0 & $1(1.5)$ & Very Low \\
\hline & & & & Marital Satisfaction \\
\hline \multirow[t]{4}{*}{$>0.001^{\S}$} & $49(60.3)$ & $37(54.4)$ & $20(29.4)$ & Too much \\
\hline & $12(17.6)$ & $19(27.9)$ & 27 (39.7) & High \\
\hline & $6(8.8)$ & $12(17.6)$ & $20(29.4)$ & Average \\
\hline & $1(1.5)$ & 0 & $1(1.5)$ & Low \\
\hline $0.622 \ddagger$ & $17(25.0)$ & $20(29.4)$ & $14(20.6)$ & Unwanted sex of baby \\
\hline $0.895^{\ddagger}$ & $9(13.2)$ & $7(10.3)$ & $8(11.8)$ & Unwanted pregnancy \\
\hline
\end{tabular}




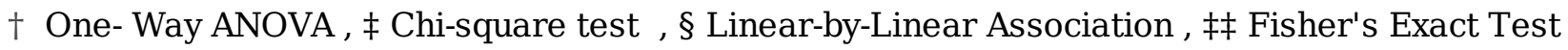

Table 2. Comparison of the scores of postpartum depression and childbirth experience in non-participation (N-P), irregularly-participation (I-P) and regularly- participation (R-P) groups

\begin{tabular}{ccccc|c|c}
\hline Variable & N-P & I-P & \multicolumn{2}{c}{ R-P } & \multicolumn{3}{c}{ comparison between groups (P-value) } \\
& Mean (SD) & Mean (SD) & Mean (SD) & N-P with R-P & N-P with I-P & I-p with R-P \\
\hline Postpartum Depression & $\mathrm{n}=68$ & $\mathrm{n}=68$ & $\mathrm{n}=68$ & $<0.001$ & $<0.001$ & 0.150 \\
& $9.3(4.7)$ & $4.9(2.3)$ & $4.1(2.2)$ & & & \\
\cline { 5 - 7 } Childbirth experience & $\mathrm{n}=44^{*}$ & $\mathrm{n}=26^{*}$ & $\mathrm{n}=51^{*}$ & $<0.001$ & $<0.001$ & 0.002 \\
& $2.3(0.3)$ & $2.9(0.4)$ & $3.2(0.4)$ & & & \\
\hline
\end{tabular}

* Because some participants underwent cesarean section before the onset of labor pain; therefore the sample size was reduced and the CEQ-2 was completed only for participants who had vaginal delivery.

Table 3. Comparison of the scores of postpartum depression and childbirth experience in the non-participation, irregularly-participation and regularly-participation groups based on the general linear model

\begin{tabular}{lccl}
\hline P-Value & 95\%Confidence Interval & B $^{*}$ & Variable \\
\hline Postpartum depression & 0 & Regular participation (Reference) \\
\hline 0.257 & -0.4 to 1.8 & 0.6 & Irregular participation \\
\hline$<0.001$ & 3.4 to 5.9 & 4.7 & Not participation \\
\hline Childbirth experience & & \\
\hline \multicolumn{2}{l}{} \\
0.032 & -0.4 to -0.02 & -0.2 & Regular participation (Reference) \\
\hline$<0.001$ & -1.0 to -0.6 & -0.8 & Not participation \\
\hline
\end{tabular}

*Values have been adjusted for spouse's education, income, occupation, spouse's occupation, spouse's support, and marital satisfaction 